\title{
Deep-sea borehole seismological observatories in the Western Pacific: temporal variation of seismic noise level and event detection
}

\author{
Masanao Shinohara $\left({ }^{1}\right)$, Ei'ichiro Araki $\left({ }^{2}\right)$, Toshihiko Kanazawa $\left({ }^{1}\right)$, Kiyoshi Suyehiro $\left({ }^{2}\right)$, \\ Masashi Mochizuki $\left({ }^{3}\right)$, Tomoaki Yamada $\left({ }^{1}\right)$, Kazuo Nakahigashi $\left({ }^{1}\right)$, Yuka Kaiho $\left({ }^{2}\right)$ and Yoshio Fukao $\left({ }^{1}\right)\left({ }^{2}\right)$ \\ (') Earthquake Research Institute, University of Tokyo, Japan \\ (2) Japan Agency for Marine-Earth Science and Technology, Yokosuka, Japan \\ $\left(^{3}\right)$ Institute of Industrial Science, University of Tokyo, Japan
}

\begin{abstract}
Seismological networks provide critical data for better understanding the dynamics of the Earth; however, a great limitation on existing networks is the uneven distribution of stations. In order to achieve a more uniform distribution of seismic stations, observatories must be constructed in marine areas. The best configuration for oceanic seismic observatories is thought to be placement of seismometers in deep boreholes. Two deep-sea borehole seismological observatories (WP-1 and WP-2) were constructed in the Western Pacific and form the initial installations of a $1000 \mathrm{~km}$ span network. At present, seismic records of more than 400 total days were retrieved from both the WP-1 and WP-2. Long-term variations in broadband seismic noise spectra $(3 \mathrm{mHz}-10 \mathrm{~Hz})$ in the Western Pacific were revealed from these records, and the data showed that ambient seismic noise levels in borehole observatories are comparable to those of the quietest land seismic stations. In addition, there is little temporal variation of noise levels in periods greater than $10 \mathrm{~s}$. Due to this low seismic noise environment, many teleseismic events with magnitudes greater than 5 were recorded. It is confirmed that seismic observation in deepsea borehole gives the best environment for earthquake observation in marine areas.
\end{abstract}

Key words deep-sea borehole observatory - broadband seismometer - seismic noise level - long-term observation

\section{Introduction}

Tomographic studies using earthquake waves propagating through the Earth's interior have revolutionized our understanding of mantle structure

Mailing address: Dr. Masanao Shinohara, Earthquake Research Institute, University of Tokyo, Tokyo 113-0032, Japan; e-mail: mshino@eri.u-tokyo.ac.jp and dynamics. One of the most important limitations on existing tomographic analyses and images of the Earth's interior is the uneven distribution of seismic stations, specifically the lack of stations situated on oceanic crust or in oceanic basins. The scientific importance of establishing long-term geophysical stations at deep ocean sites has been acknowledged by the Earth science communities and is detailed in various reports (e.g., ION/ODP International Workshop, 1995). The objective of tomographic studies is to understand the structure and dynamics of the tectonic system from a regional to global scale by imaging the Earth's interior with seismic waves. Unfortunately, few seismometers are sited on the $71 \%$ of the Earth's surface covered by oceans. 
The asymmetry and non-uniformity of the seismic station distribution makes high-resolution imaging of some parts of the mantle nearly impossible. Many ocean bottom geophysical sensors, whose locations have been carefully selected to optimize imaging, are needed around the world to attain the goals of the various international geoscience programs. The Japanese Ocean Hemisphere Network Project (OHP: 1996-2002, http://eri-ndc.eri.utokyo.ac.jp/en/ohp/index.html) selected the Western Pacific area for installation of ocean-bottom sensors because it is ideal for addressing problems related to plate subduction. Based on the results of previous studies using borehole seismometers on the seafloor, it is becoming clear that emplacement of seismometers into the igneous crust using boreholes can provide low noise environments (Kanazawa et al., 1992; Suyehiro et al., 1992; Montagner et al., 1994; Beauduin and Montagner, 1996; Romanowicz et al., 1998; Stephen et al., 1999; Collins et al., 2001; Araki et al., 2004). However there are no observational records covering a span of more than a half year in any deep-sea borehole observatory. The OHP installed four borehole geophysical stations at three sites covering a period from 1999 to 2001 (fig. 1). In 1999, two borehole stations (JT-1 and JT-2) were installed during ODP Leg 186 (Sacks et al., 2000) and are located immediately above the inter-plate earthquake generation zone on the landward side of the Japan Trench. The JT-1 and JT-2 stations were installed approximately $50 \mathrm{~km}$ apart and have two broadband seismometers, a strainmeter and a tiltmeter for each station. In August 2000, during ODP Leg 191, the borehole seismological observatory WP-2 was successfully installed at ODP Site 1179 in the northwestern Pacific Basin (Kanazawa et al., 2001). Borehole seismic observatory WP-1 was installed in the west Philippine Basin during ODP Leg 195 in April 2001 (Salisbury et al., 2002). The WP-1 and WP-2 observatories each have two identical broadband seismometers. Together, these observatories can cover a large expanse of the northwestern Pacific in areas that comprise major gaps in the coverage provided by pre-existing global seismological observatories. At present, the data from these four borehole observatories are retrieved by ROV visits at an interval of about 0.5-1.5 year (Suyehiro

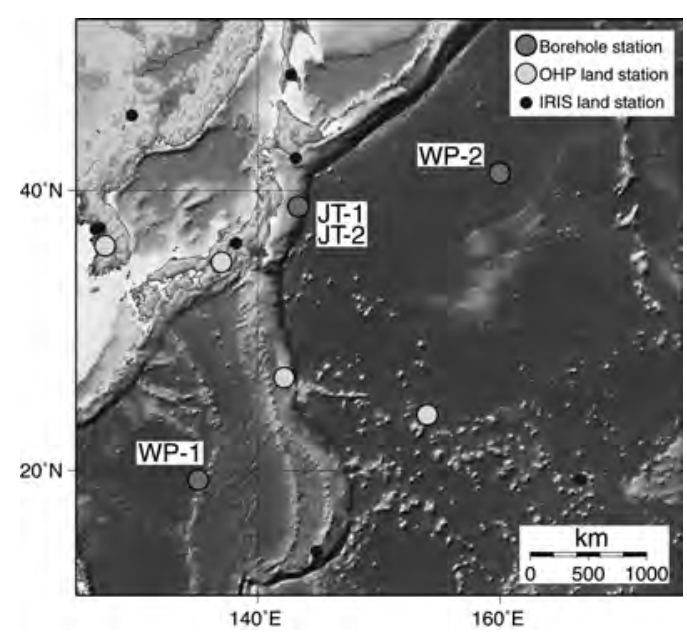

Fig. 1. Location map of seismic station coverage in the northwest Pacific. Small black and light gray circles indicate land seismic stations, dark gray circles are seafloor borehole observatories. The WP-1 and WP-2 observatories were installed in August 2000 and April 2001, respectively. Note that a few borehole stations can effectively complement and expand the existing network.

et al., 2002). Araki et al. (2004) have already reported on the JT-1 and JT-2 observatories and the characteristics of the geophysical data obtained from the JT-1 Observatory. In this paper, we describe the characteristics, layout, and system parameters of the WP-1 and WP-2 seismological observatories, and the characteristics of the seismic data retrieved from them, specifically the ambient seismic noise levels, temporal noise variations, and performance of the observatories.

\section{Deep-sea borehole seismological observatories WP-1 and WP-2}

\subsection{System}

The WP-1 and WP-2 seismic observatories were designed to work for more than five years as stand-alone systems. Because the characteristics of the WP-1 and WP-2 observatories have already been described in detail (Kanazawa et al., 2001; Salisbury et al., 2002), we explain their 

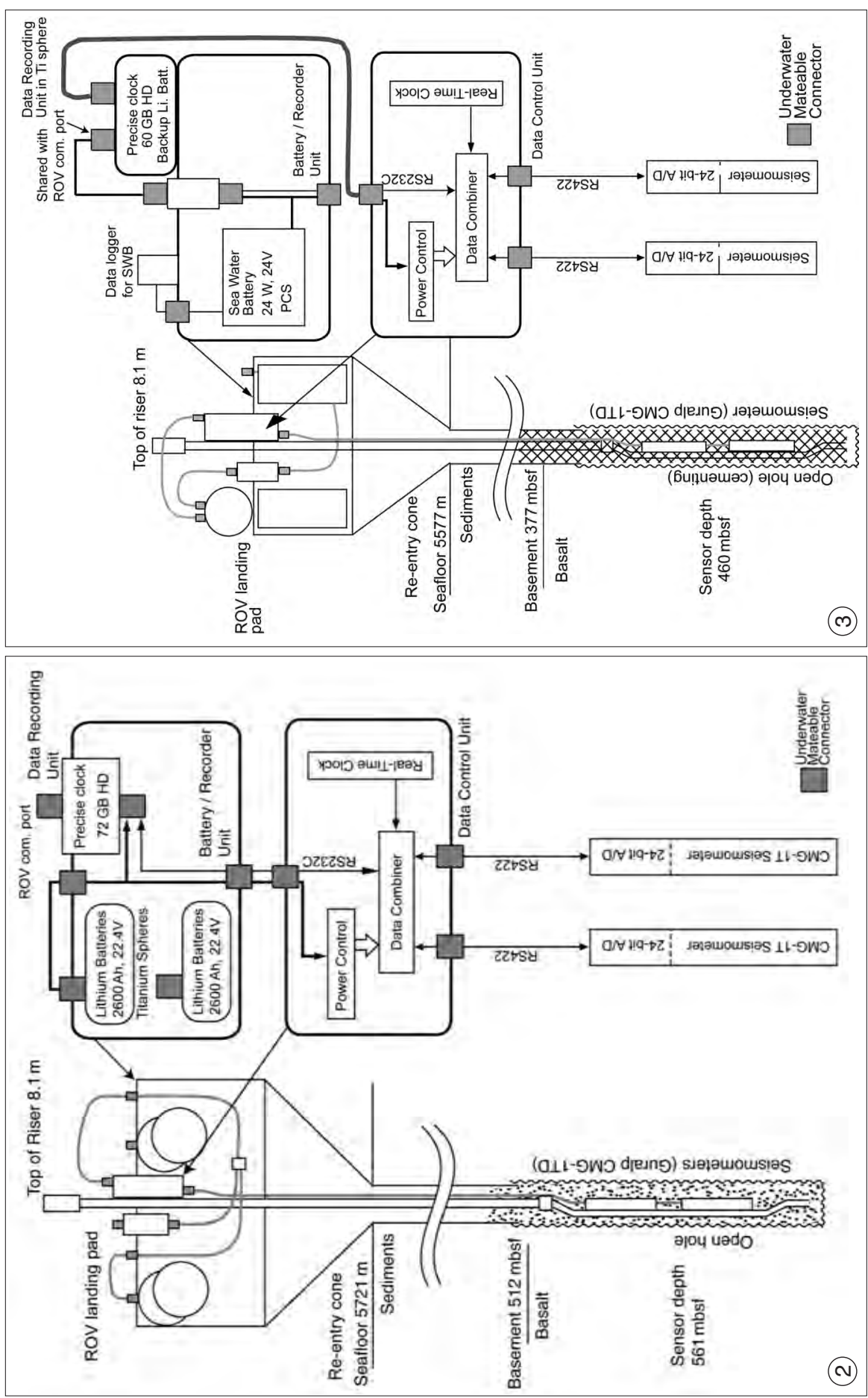

을

3

خे

흘

స్త.

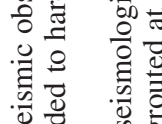

F⿻十

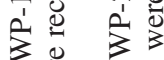

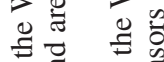

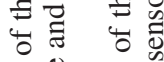

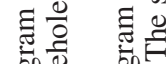

:

苍邱

응 능 훙

.

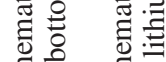

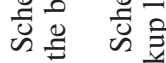

ن 䒕

番兽 
design and layout briefly here. Both systems are basically identical except for the power supply (figs. 2 and 3). There is a retired co-axial transoceanic telephone cable near the WP-1 Observatory that will be utilized in the future for data recovery and power supply. Presently, however, both observatories work as stand-alone systems with their own batteries and recorders. Two broadband seismometers (Guralp CMG-1TD) were placed near the bottom of the borehole in igneous basement. The seismometers were emplaced in the borehole permanently; they were cemented into the hole in order to assure good coupling with the surrounding crust. The signals are digitized in the sensor packages and sent in digital form to the seafloor data-recording packages. The seafloor package serves to combine the digital data from the two seismometers to a single serial data stream. The data are stored to a data recorder in a digital format via a RS-232C link. Because the recorder unit can be recovered by an ROV, the recorder has been improved in concert with the improved electronics packages developed over the past few years. At present, the recorder has four $30 \mathrm{~Gb}$ SCSI hard disks equivalent to more than 6 channels of one-year continuous data of 24 bit dynamic range at a 100 $\mathrm{Hz}$ sampling rate. The recorder unit also provides a communication link to the borehole system. The status of the observatory can be checked via an «ROV interface» that enables RS-232C communication between the recorder and the ROV during an ROV visit.

The major difference between the WP-1 Observatory and the WP-2 Observatory is in the electric power supply system. For the WP-1 Observatory, power is supplied from a Lithium Battery System (LBS) consisting of two units, each comprising sixteen lithium cells. Eight of these cells are connected serially and two series are connected in parallel, and each unit has a capacity of $2600 \mathrm{Ah}$. Each battery unit is contained in two titanium spheres with a diameter of $65 \mathrm{~cm}$. The battery system should, based on system specifications, provide power to the observatory for $\sim 2.5$ years. Electric power for the WP-2 Observatory is supplied from a Sea Water Battery (SWB) (Hasvold et al., 1997), which can supply up to $\sim 24 \mathrm{~W}$ with more than $400 \mathrm{kWh}$ capacity. The power is derived from electrolytic dissolution of a magnesium anode in seawater, and power generation is dependent on seawater conditions (salinity, temperature). Because the performance of the SWB depends on the condition of seawater, additional lithium batteries are used as a backup power supply. All the seafloor instruments and the magnesium anode of the SWB are designed to be replaceable by ROV.

\subsection{Installation}

Installation of the seismometer systems for the WP-1 and WP-2 observatories was performed in April, 2001 and August, 2000, respectively. Each of the boreholes was drilled through sedimentary rock into basaltic oceanic basement, and the seismometers were installed in the basaltic sections of the boreholes. The seismometers were supported on $4.5^{\prime \prime}$ diameter casing pipe hanging on the base of a permanent reentry cone mounted on the mouth of the borehole at the seafloor (fig. 4). This pipe provided a basis for instrument insertion and a conduit for cement pumping for anchoring of the seismometers. Grouting cement was pumped through the casing pipe, and then up around the seismometers. The seismometers were grouted at depths of $561 \mathrm{~m}$ below seafloor (mbsf) and $460 \mathrm{mbsf}$ in basement rock $19 \mathrm{~m}$ and $15 \mathrm{~m}$ above the bottom of the boreholes for WP1 and WP-2, respectively. After cementing, the drill pipe from the ship was decoupled and withdrawn leaving the casing pipe in the hole. The power and data cables attached to the seismometer and leading to the data recording and power supply were protected from wear and chafing by being anchored to the casing pipe and are protected from wall contact by centralizers. The cable itself is designed to be almost neutrally buoyant in seawater, further minimizing long term stress on the cables.

After cementing of the seismometers was complete, assembly of the battery/recorder unit was accomplished onboard, and the battery/recorder unit was lowered through the moon pool on drilling deck of the Joides Resolution and mounted on the reentry cone, after which time the batteryrecorder unit was released from the ship via acoustic signal and the drill string was recovered. 


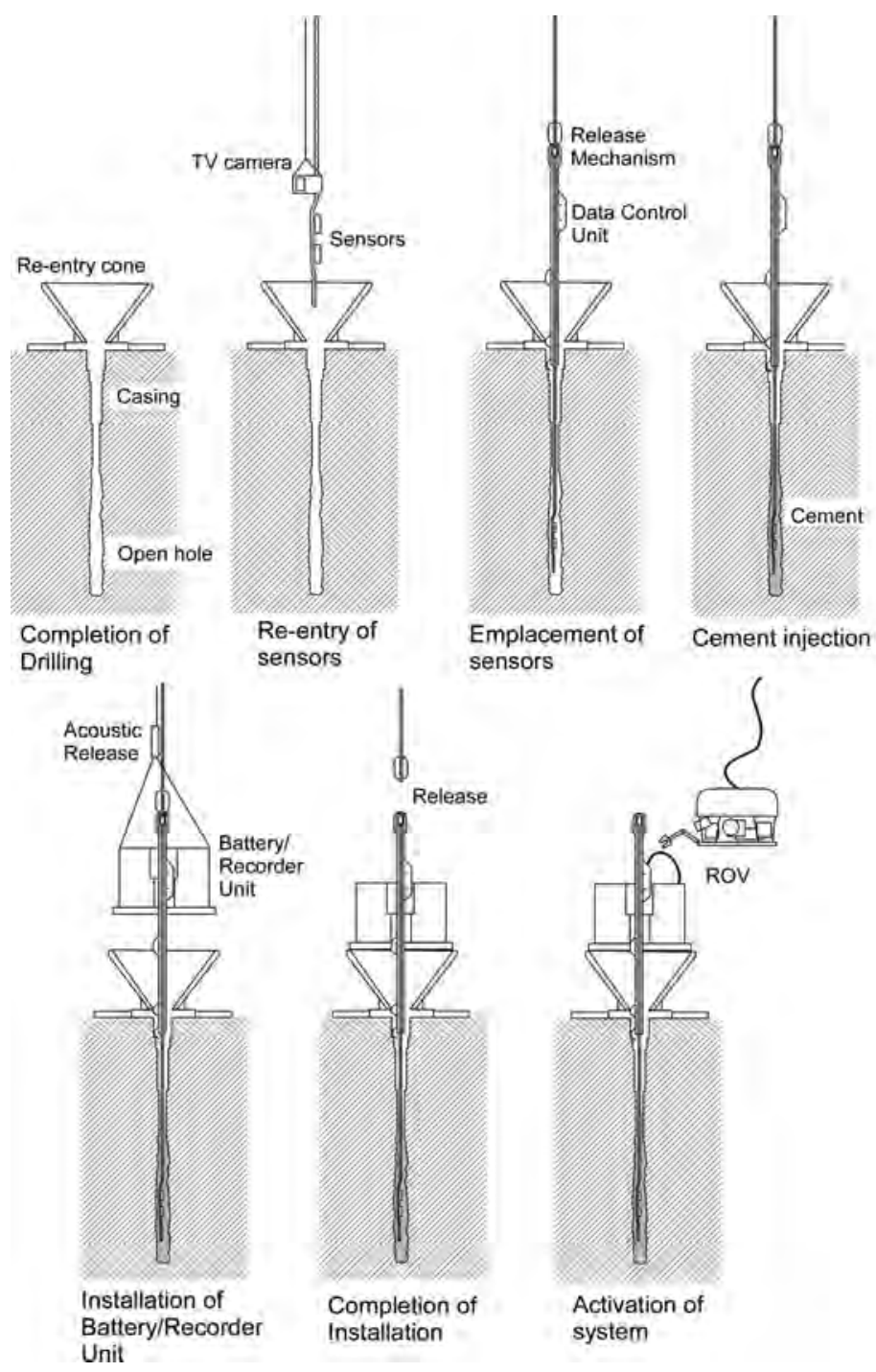

Fig. 4. Installation procedure of the deep-sea borehole broadband seismic observatory. After completion of drilling, the sensor string assembly was lowered into the hole. Because a TV camera was needed for the re-entry of the sensor string assembly, the sensors could not be connected to the batteries and data recorder on the seafloor. The cement was displaced down hole for fixing of the sensors. The battery/recorder unit was lowered along the drill string and was released by an acoustic command. After installation, an ROV was used to activate the system.

\subsection{System activation and data recovery}

In March 2002, KAIKO, a full-ocean depth ROV belonging to the Japan Marine Science and
Technology Center (JAMSTEC), visited the WP1 site to activate the observatory, and long-term observation was started using the first LBS unit. Both the seismometers at the WP-1 were con- 
firmed to work properly from the R/V Kairei via an RS-232C link, one seismometer was deactivated to decrease power consumption. In October 2002, the KAIKO re-visited the WP-1 site and we obtained $\sim 6$ months of continuous data (Mar 26October 6, 2002) (fig. 5). The KAIKO visited the WP-1 site again in May 2003 and $\sim 7$ months of continuous data (October 7, 2002-May 7, 2003) were retrieved. During the third visit, the KAIKO changed an electric connection and the second LBS unit was put on line to supply the power to the system. At present, seismic records of 408 days in total have been obtained from the WP-1 Observatory.

The WP-2 Observatory was activated in October 2000 using the ROV KAIKO. Since the performance of Sea Water Batteries (SWB) depends on the environment around the deployed position, there was a possibility that SWB could not generate enough power for the whole system. Therefore, we decided to operate WP-2 using lithium batteries during the first observation period as the preliminary observation and had developed a lithium battery system, which supplies the power to the system. The lithium battery system consists of five lithium batteries with a total capacity of $1300 \mathrm{AH}$. Only one seismometer was activated in

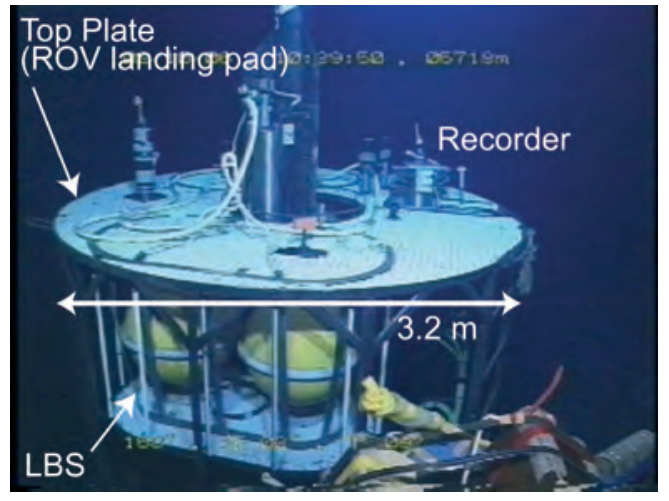

Fig. 5. An ROV view of the WP-1 station after the maintenance of the system (October 6, 2002). The power is supplied from lithium batteries in the titanium spheres (Lithium Battery System unit). Top of the battery frame is also used as an ROV landing pad. The data recorder package can be seen on top of the battery/recorder unit.

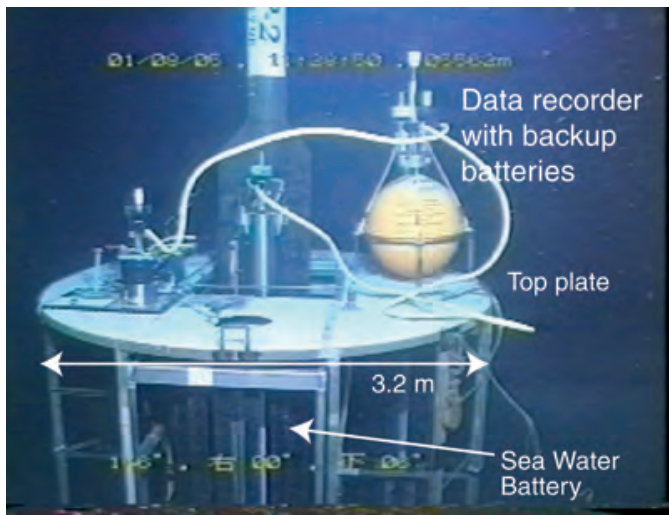

Fig. 6. Installation of the titanium sphere containing the data recorder and the lithium batteries as backup at the top of the platform for long-term observation for the WP-2 station (August 5, 2001). The power is mainly supplied from the Sea Water Battery system. The SWB system has four SWB1200 cells. The cell is a magnesium and oxygen battery based on a magnesium anode that uses seawater as the electrolyte. When voltage from the SWB is dropped, the lithium batteries in the sphere supply backup power.

Table I. Summary of observation period of the WP1 and WP-2 observatories.

WP-1 Observatory WP-2 Observatory

\begin{tabular}{lcc} 
Installation & $\begin{array}{c}\text { ODP Leg 195 } \\
\text { April, 2001 }\end{array}$ & $\begin{array}{c}\text { ODP Leg 191 } \\
\text { August, 2000 }\end{array}$ \\
Activation & March 26, 2002 & October 29, 2000 \\
Data periods & March 26, 2002- & October 29, 2000- \\
& October 6, 2002 & January 21, 2001 \\
& October 7, 2002- & August 3, 2001- \\
& May 7, 2003 & June 30, 2002 \\
Total & 408 days & 417 days \\
Status & In operation & In operation \\
\hline
\end{tabular}

order to minimize power consumption, similar to the case for WP-1. In August 2001, the KAIKO re-visited the WP-2 site. Approximately threemonths of continuous data (October 29, 2000January 21, 2001) were recovered. During the second visit, it was confirmed that the SWB system continued working properly, and long-term observation using both the SWB and backup 
lithium battery system was initiated (fig. 6). When the SWB generates enough electric power for the system, the system is supplied the power from the SWB. If the SWB cannot generate the power, the backup lithium battery system supplies the power to the system. The backup lithium battery system can supplies the power for approximately three months. The KAIKO visited the WP-2 site again in June 2002 and 11 months of continuous data (August 3, 2001-July 29, 2002) were retrieved for the second observation period. The KAIKO also recovered the monitoring data for the SWB system, confirming that the SWB system worked continuously for almost one year. The operation details of the WP-1 and WP-2 observatories until the end of 2003 are summarized in table I.

\section{Seismic records from the WP-1 and WP-2 observatories}

\subsection{Background seismic noises in deep-sea boreholes}

The seismic data from the WP-1 and WP-2 seismological observatories enable the study of broadband seismic noise in the frequency range from $3 \mathrm{mHz}$ to $50 \mathrm{~Hz}$ in the northwestern Pacific over a period covering more than one year of continuous recording. Temporal changes in ambient seismic noise within deep-sea borehole can be analyzed in depth using this data.

Figure 7a-d shows the noise level as a function of time and period for vertical and horizontal components of the WP-1 and the WP-2 observa-
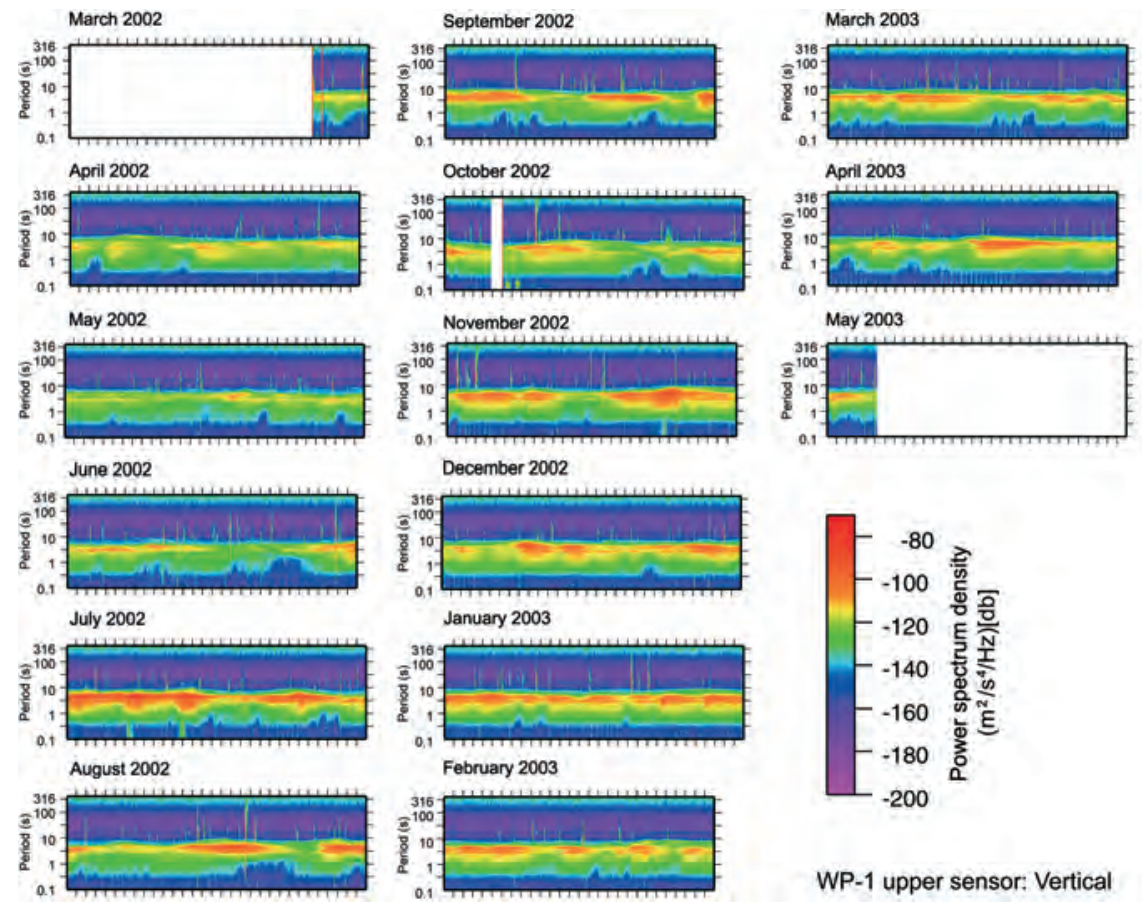

WP-1 upper sensor: Vertical

Fig. 7a. Running spectra of the records from the deep-sea borehole observatories. Each spectrum is calculated with a moving time window for a total of one hour record. Here the spectra are for the vertical component of the WP-1 Observatory. There is little change in noise levels above $10 \mathrm{~s}$ period. Many earthquakes are visible on the running spectra in periods greater than $10 \mathrm{~s}$. Small temporal variations (maximum fluctuation is $10 \mathrm{~dB}$ ) of noise levels for periods around a few seconds are seen. 

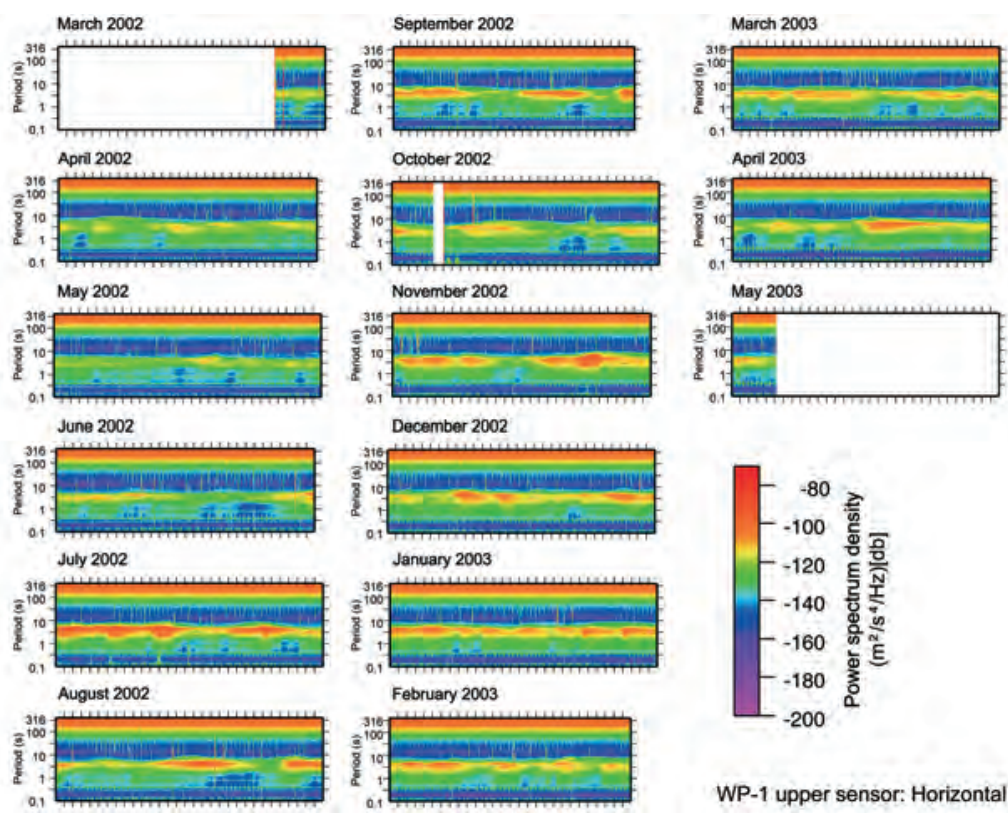

WP-1 upper sensor: Horizontal

(b)
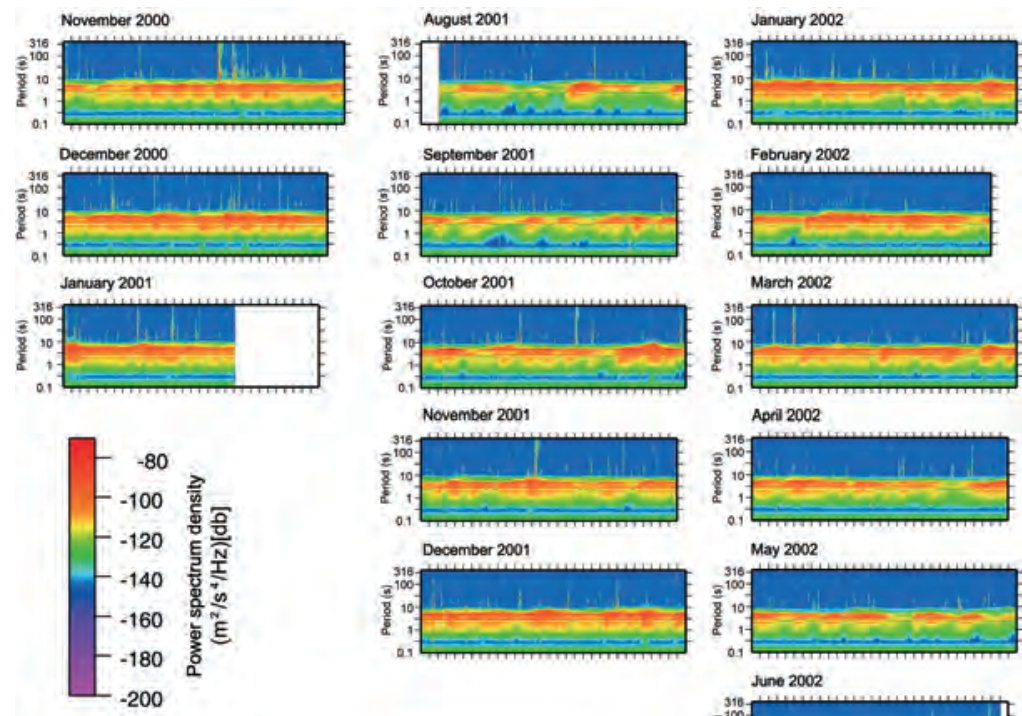

WP-2 upper sensor: Vertical

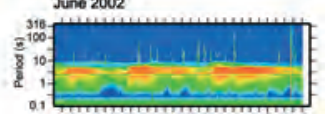

Fig. 7b,c. Running spectra of the records from the deep-sea borehole observatories. Each spectrum is calculated with a moving time window for a total of one hour record. b) Spectra for the horizontal component of WP-1. A total of 408 days of continuous data were obtained form the WP-1 Observatory. c) Spectra for the vertical component of the WP-2 Observatory. A total of 417 days of continuous data were retrieved from WP-2. There is little change in noise levels above $10 \mathrm{~s}$ period. Many earthquakes are visible on the running spectra in periods greater than $10 \mathrm{~s}$. Small temporal variations (maximum fluctuation is $10 \mathrm{~dB}$ ) of noise levels for periods around a few seconds are seen. 

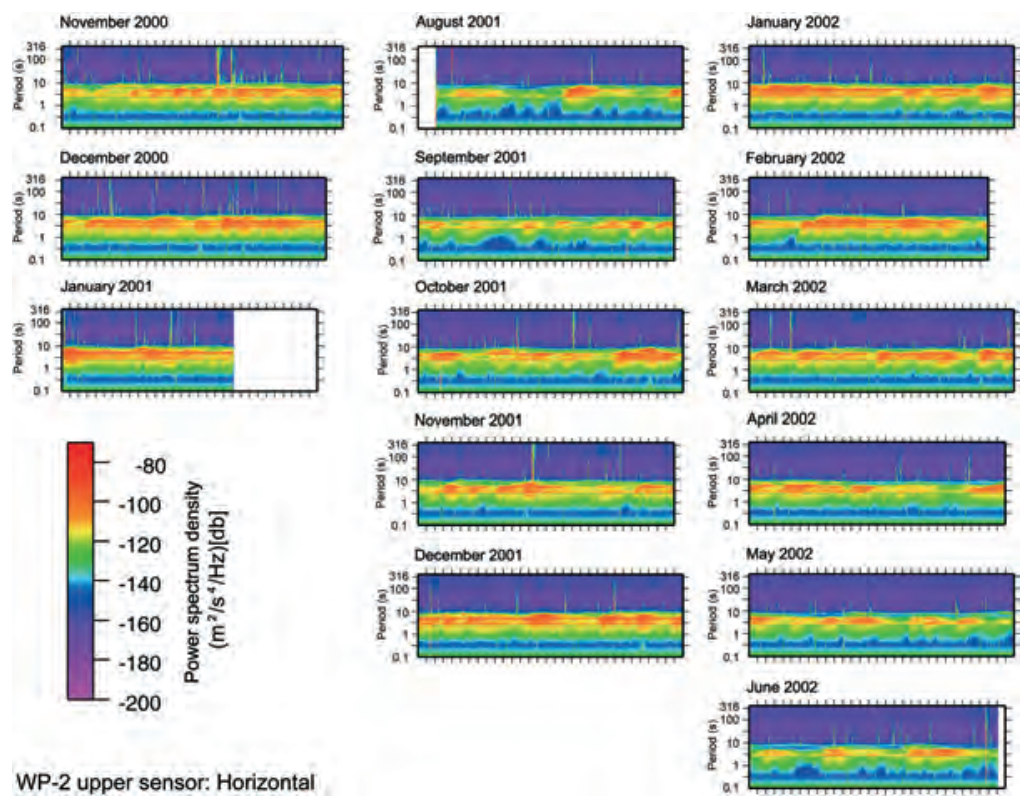

WP-2 upper sensor: Horizontal

Fig. 7d. Running spectra of the records from the deep-sea borehole observatories. Each spectrum is calculated with a moving time window for a total of one hour record. Here the spectra are for the horizontal component of WP-2. A total of 417 days of continuous data were retrieved from WP-2. There is little change in noise levels above $10 \mathrm{~s}$ period. Many earthquakes are visible on the running spectra in periods greater than $10 \mathrm{~s}$. Small temporal variations (maximum fluctuation is $10 \mathrm{~dB}$ ) of noise levels for periods around a few seconds are seen.

tories. Each spectrum is calculated with a time window of about four minutes shifted every two minutes and is averaged for a total of one hour record. All spectra for one hour are plotted as a function of time. The major advantage of borehole observatories is that there are little or no temporal changes in noise levels for periods longer than $10 \mathrm{~s}$. Vertical high-level bars in the running spectra indicate earthquakes. In contrast, small temporal variations (maximum fluctuations of $10 \mathrm{~dB}$ ) in noise levels for periods around a few seconds are seen.

All power spectrum densities calculated using the moving window for every one hour are plotted as a function of periods (fig. 8a-d), and the spectra are grouped by seasons. It is confirmed from fig. 8a-d that the noise levels for both vertical and horizontal components of the both the WP-1 and WP-2 observatories for periods of greater than $10 \mathrm{~s}$ are stable year round. It is found that the noise levels in the vertical component at the WP-1 reach $-180 \mathrm{db}$ for time-periods between $10 \mathrm{~s}$ and $100 \mathrm{~s}$. On the other hand, small temporal changes of noise levels in periods around a few seconds are seen. The WP-1 Observatory recorded relatively large noise levels in summer and fall. The vertical component of the WP-2 Observatory has minimum noise levels about $-145 \mathrm{db}$. The noise levels in the horizontal component in the WP-2 seismometer are $-160 \mathrm{db}$ for time-periods between $10 \mathrm{~s}$ and $100 \mathrm{~s}$ and are lower than that of the vertical component. The records from the WP-2 Observatory reveal high noise levels in a period range of a few seconds during winter. For both the vertical and the horizontal components of both the observatories, the noise levels are close to the Low Noise Model (Peterson, 1993) near the $10 \mathrm{~s}$ period. In general, the peak in noise spectrum near a period of $100 \mathrm{~s}$ in measurements taken at the seafloor or in a shallow-sea borehole is due to deformation of the seafloor by ocean gravity waves (Webb, 1998). 

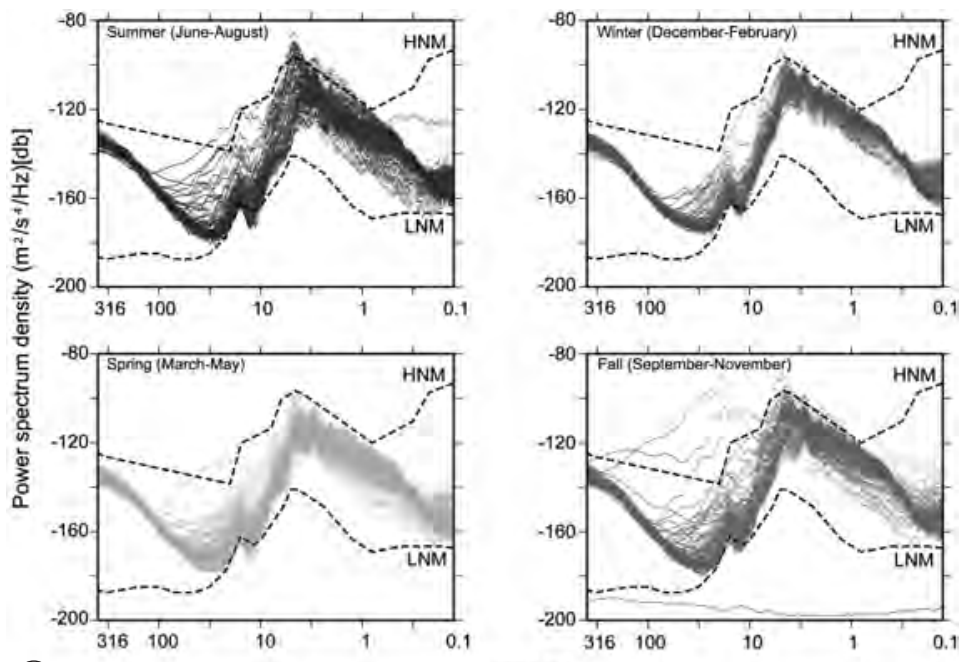

(a)
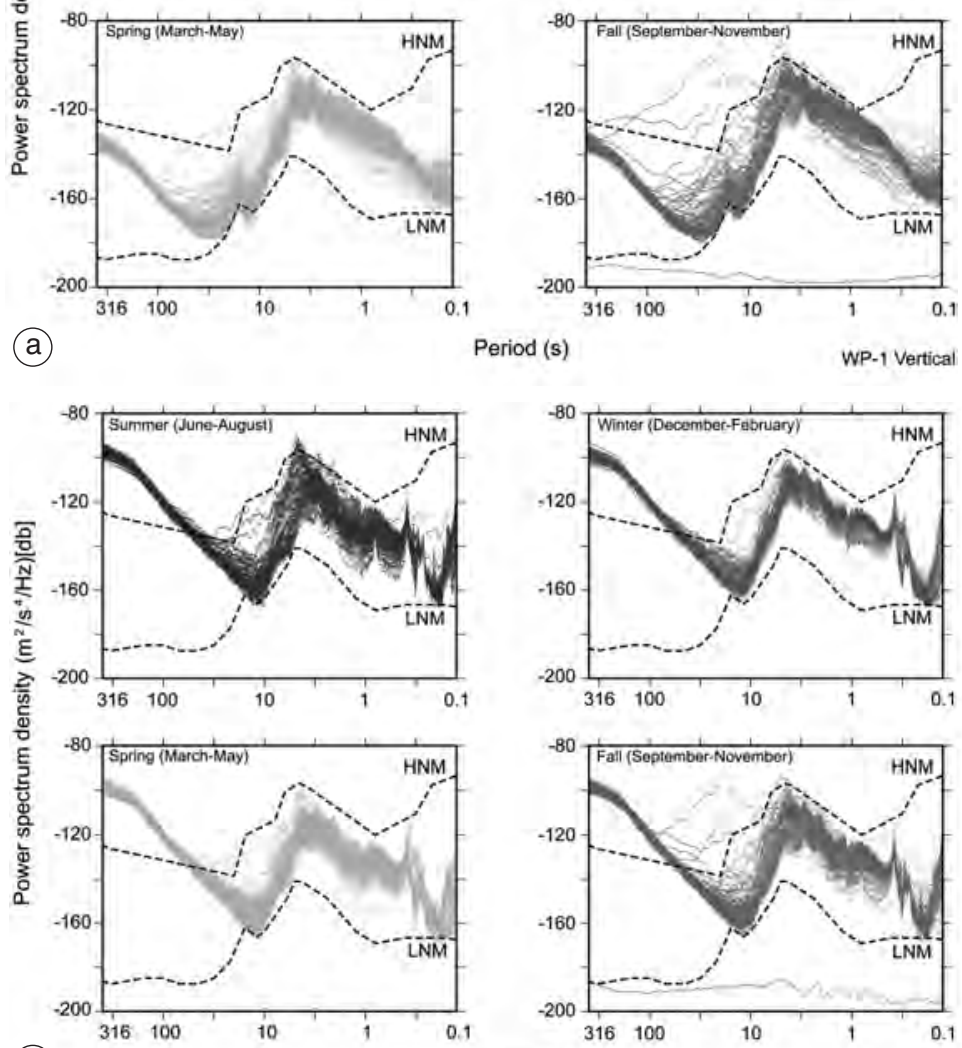

(b)

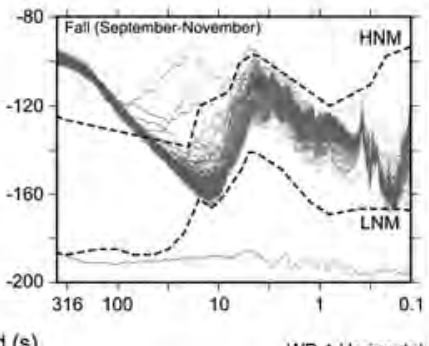

Period (s)

WP-1 Horizontal

Fig. 8a,b. Power spectra of the deep-sea borehole seismic observatories. Power spectra estimated using onehour records for the all observation period are plotted. HNM and LNM indicate the high noise model and the low noise model by Peterson (1993), respectively. The power spectra are grouped by seasons: a) for vertical component of WP-1; b) for horizontal component of WP-1. The horizontal component records of the WP-1 Observatory have larger noises in periods longer than $20 \mathrm{~s}$. The records of the WP-1 have larger noise levels near a few seconds period in summer.

Araki et al. (2004) reported that installation of a seismometer in the basement rocks minimize the effect of the ocean gravity wave. Because all the seismometers of the WP-1 and WP-2 observato- ries were installed into basaltic basement, there is no peak due to the ocean gravity waves.

The horizontal component records of the WP1 Observatory have larger noise levels than the 
vertical component records for periods longer than $20 \mathrm{~s}$. There is a possibility that the horizontal sensors in the WP-1 seismometer have a coupling problem. In addition, the noise level of the vertical component for period longer than $10 \mathrm{~s}$ in the WP-2 Observatory is larger than those of the horizontal component. Because the vertical sensor of the WP-2 Observatory may have some
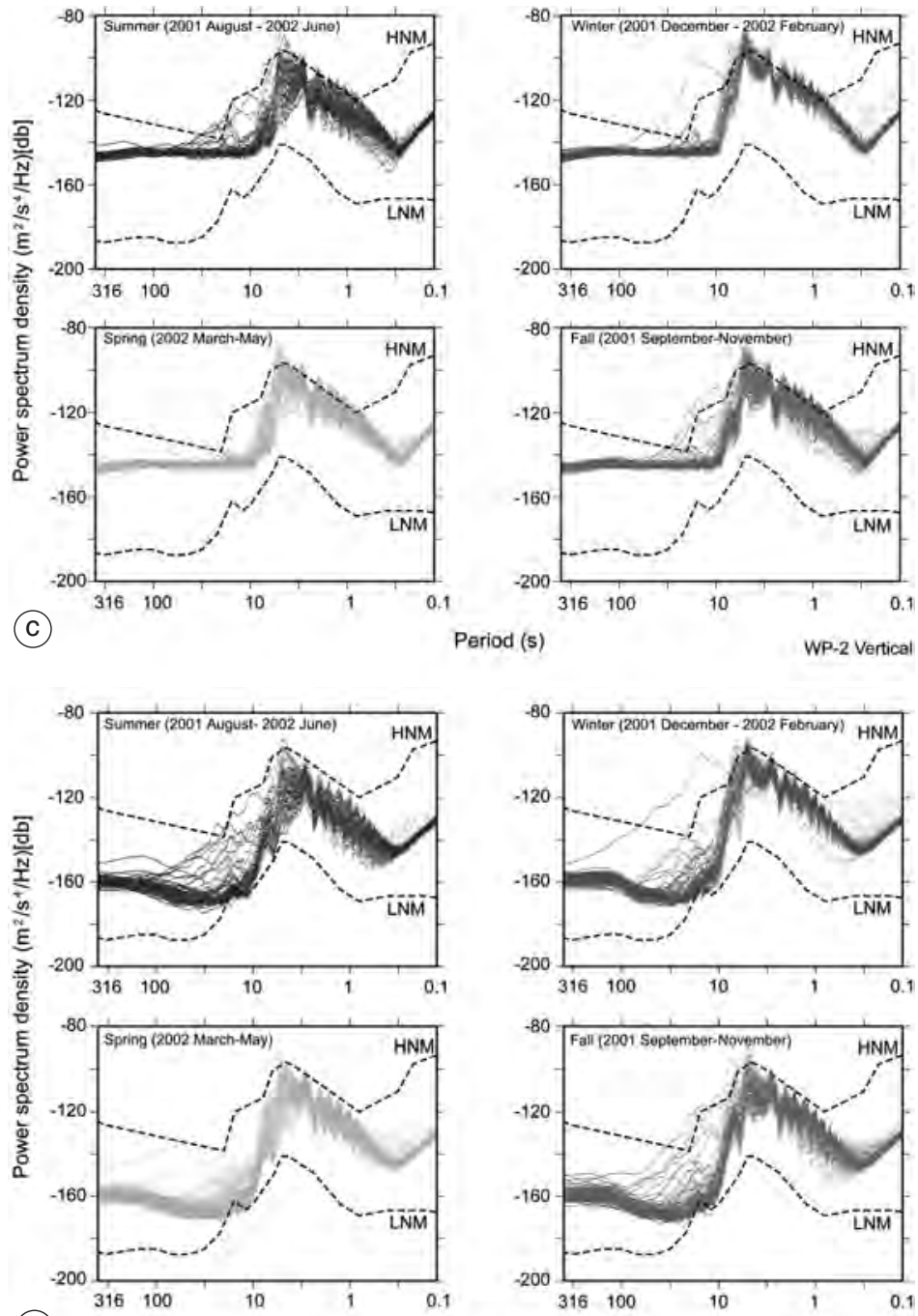

(d)

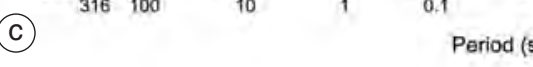

WP-2 Vertical

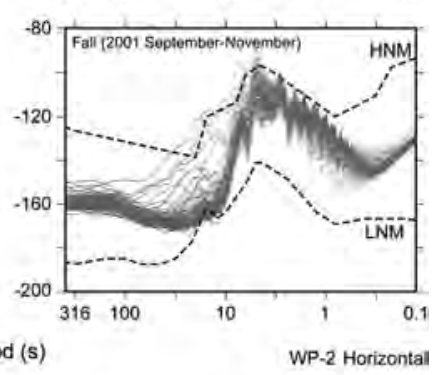

Fig. 8c,d. Power spectra of the deep-sea borehole seismic observatories. Power spectra estimated using one-hour records for the all observation period are plotted. HNM and LNM indicate the high noise model and the low noise model by Peterson (1993), respectively. The power spectra are grouped by seasons: c) for vertical component of WP2. The vertical component records of the WP-2 Observatory have also larger noise levels in periods longer than 10 s. d) For horizontal component of WP-2. The WP-2 Observatory has quiet noise environment in summer. 
damage, we switched the sensor to the alternative in June 2002. At present, we have not obtained records from the alternative sensor in the WP-2 Observatory.

\subsection{Comparison with meteorological data}

Wind speeds on the Earth surface are considered to increase seismic noise level at high frequency $(>0.1 \mathrm{~Hz})$ with increasing velocity (Wilcock et al., 1999; Collins et al., 2001). A small island (Okinotori-shima) lies about $150 \mathrm{~km}$ northeast from the WP-1 Observatory. A meteorological observatory is being operated at the Okinotorishima by JAMSTEC, and average wind speed, maximum wind speed, wind direction, air temperature, humidity, air pressure, insolation, and radiation are observed every $30 \mathrm{~min}$. Comparison of the noise spectra of the vertical component of the WP-1 seismometer with average wind speed and atmospheric pressure (fig. 9a,b) indicates that wind speed seems to be related to noise levels for periods around a few seconds. Specifically, typhoon 200225 passed near the Okinotori-shima Island on November 23, 2002. Large noise levels for a few second periods at WP-1 were observed around November 23, 2002. For the WP-2 Observatory, the high seismic noise level in winter is observed. Although there is no meteorological station near the WP-2, it is known that the northwestern Pacific has strong winter winds due to dominant low-pressure weather systems. We infer that wind speed is also related with the seismic noise level of the WP-2.

\subsection{Teleseismic events and performance of event detection}

The WP-1 and WP-2 deep-sea borehole seismic observatories reside in a quiet environment
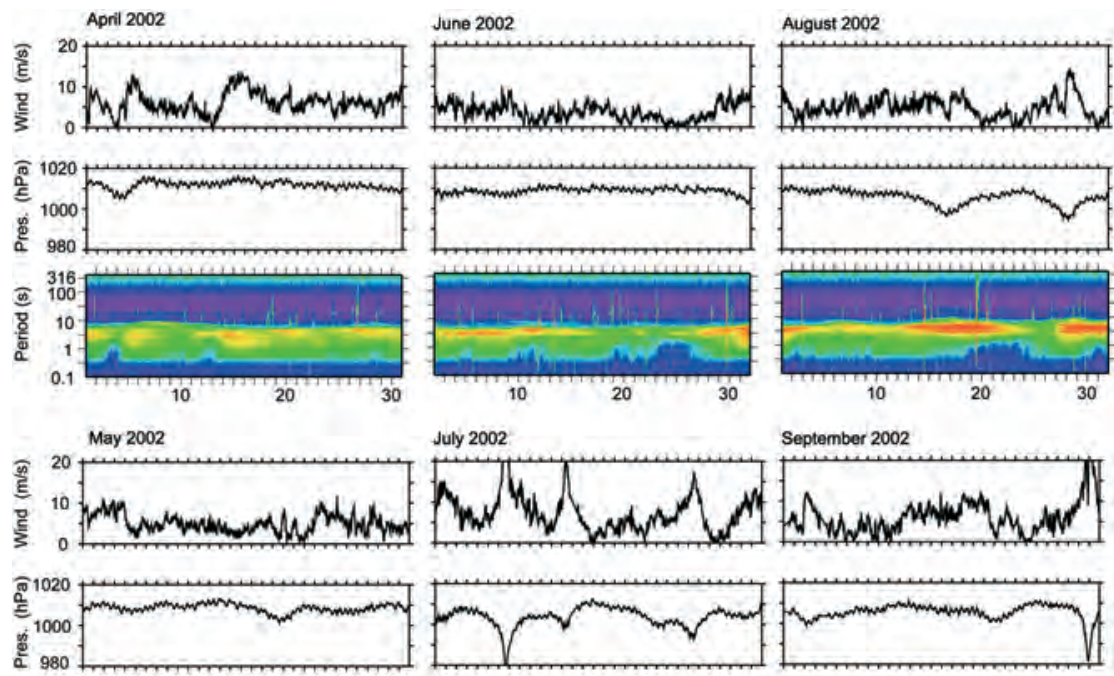

July 2002

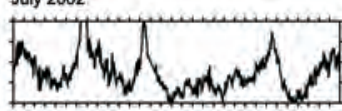

September 2002
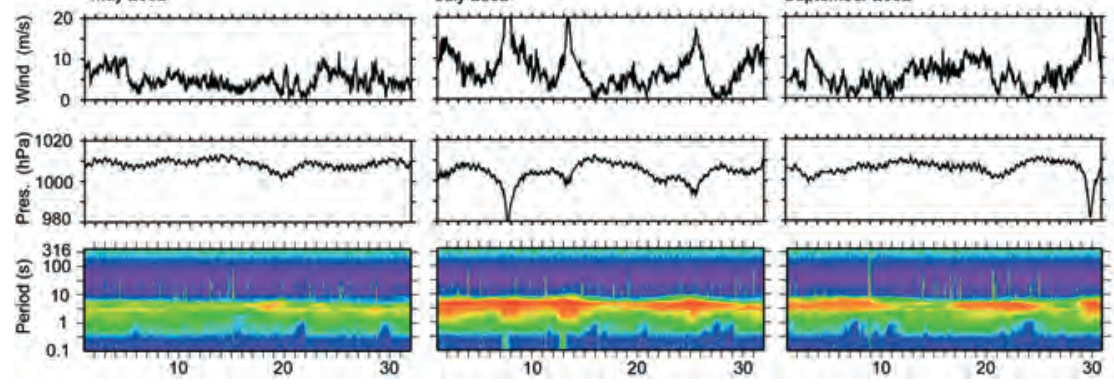

Fig. 9a. Comparison between the noise spectra of vertical component of the WP-1 and the meteorological data (average wind speeds and air pressure) observed at Okinotori-shima, which lies about $150 \mathrm{~km}$ northeast of WP-1: from April to September 2002. Rapid decreases of air pressure indicates typhoon passing. The wind speed appears to be related to noise levels in periods around a few second. 

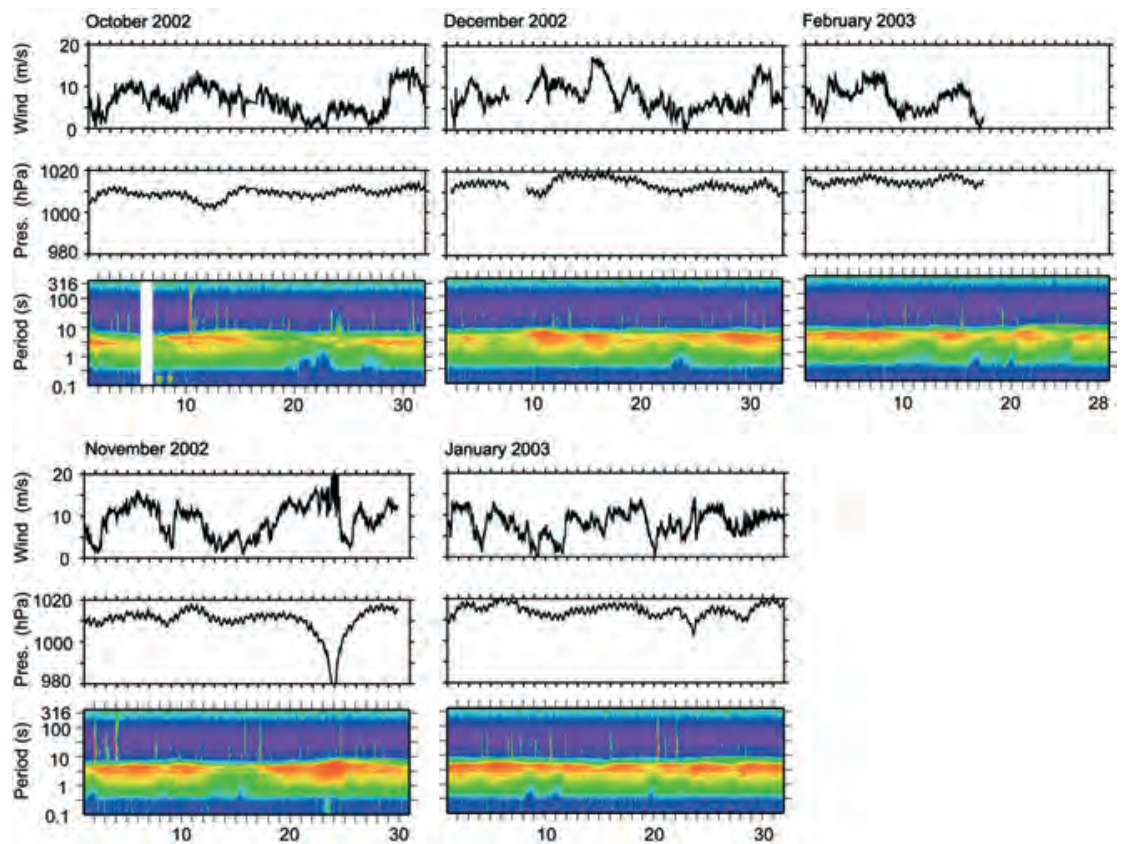

Fig. 9b. Comparison between the noise spectra of vertical component of the WP-1 and the meteorological data (average wind speeds and air pressure) observed at Okinotori-shima, which lies about $150 \mathrm{~km}$ northeast of WP-1: from October 2002 to January 2003. Rapid decreases of air pressure indicates typhoon passing. The wind speed appears to be related to noise levels in periods around a few second.

suitable for earthquake observation. Specifically, stable ambient seismic noise levels in marine areas enables us to record many teleseismic events uniformly in time. Figure 10 shows three component seismograms of the teleseismic event that occurred on November 15, 2002 in the region of South Sandwich Island $\left(M_{s}=6.6\right)$ and was recorded at the WP-1 Observatory. The seismogram clearly shows minor- and major-arc Love and Rayleigh waves. At present, we have data obtained simultaneously from both the WP-1 and WP-2 observatories for events that occurred between March 26 and June 30, 2002. For example, an earthquake that occurred in the Mariana Islands region at a depth of $86 \mathrm{~km}$ on April 26, 2002 $\left(m_{b}=6.6\right)$ was observed at both the WP-1 and the WP-2 observatories (fig. 11). Simultaneous observation and data recording by both the WP-1 and WP-2 observatories continues to the present.

To investigate the performance of the deepsea borehole seismic observatory, we plotted all vertical seismograms obtained at the WP-2 Observatory from October 29, 2000 to January 21, 2001 and manually picked events from the plot. The seismograms were filtered between periods of 20 and $500 \mathrm{~s}$. A list of recorded events by the WP-2 observatories was compared to a list published by the USGS (the Quick Epicenter Determinations). As a result, the deep-sea borehole observatory proved to record all the teleseismic events with magnitudes greater than 5 at this frequency band (fig. 12). Because there is little temporal variation of ambient seismic noise, we can obtain more than one seismic event per a day from the deep-sea borehole seismic observatories. The WP-2 Observatory records many events that are not included in the list of the QED, USGS. Most of these events were identified by the Japanese seismic network and their magnitudes are less than 4 . The epicentral distances of the regional events with magnitudes less than 4 are less than $2000 \mathrm{~km}$. On the other hand, there is no ob- 

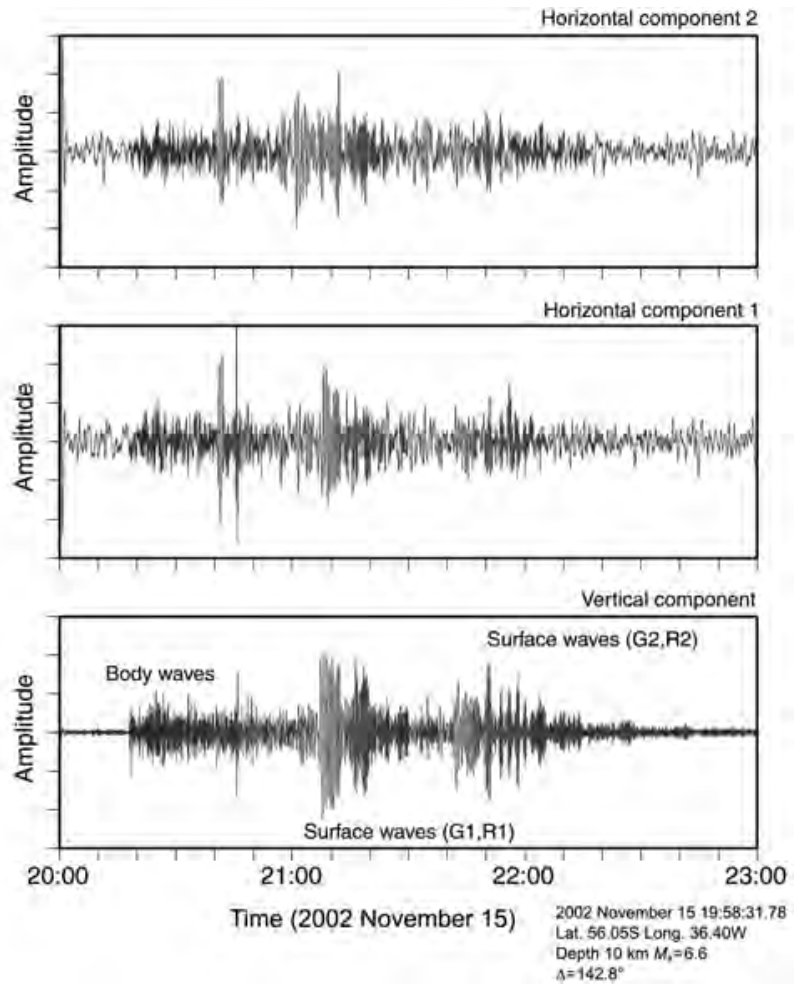

Fig. 10. Example of observed earthquake at the WP-1 Observatory. All the components are shown. The records were band-pass filtered at periods from $50 \mathrm{~s}$ to $5 \mathrm{~s}$. The earthquake occurred in the region of South Sandwich Islands on November 15, 2002, and had a magnitude of 6.6. Epicenteral distance is about $143^{\circ}$. Minor- and major-arc Love and Rayleigh waves are clearly seen.

servation of local earthquake whose $S-P$ time is less than $10 \mathrm{~s}$ for both the WP-1 and the WP-2 observatories, because both the WP-1 and the WP-2 are placed in inactive deep-sea basins.

\subsection{Comparison with previous deep-sea borehole observations}

Prior to our observation, several deployments of broadband seismometers into boreholes on the seafloor had been carried out and ambient seismic noise spectra were obtained in the Atlantic Ocean and the Pacific Ocean off Hawaii (Montagner et al., 1994; Beauduin and Montagner, 1996; Stephen et al., 1999; Collins et al., 2001). We compare the ambient seismic noise spectra from the WP-1 and the WP-2 observatories with those in previous deep-sea borehole observations (fig. 13a,b). For both vertical and horizontal components, noise levels in periods smaller than a few seconds are similar, however there are some differences for periods greater than $10 \mathrm{~s}$. For the vertical component, the WP-2 Observatory has larger noise level than the other deep-sea borehole observatories in periods between 10 and 100 s. On the other hand, the WP-1 Observatory and the OSN-1 Observatory, the latter of which was installed in the Pacific Ocean off Hawaii, are quiet in this frequency band for the vertical component. Noise levels of both observatories are comparable to those of quietest seismic station on land at periods between $10 \mathrm{~s}$ and $30 \mathrm{~s}$. There is a possibility that at least one of the sensors for ver- 


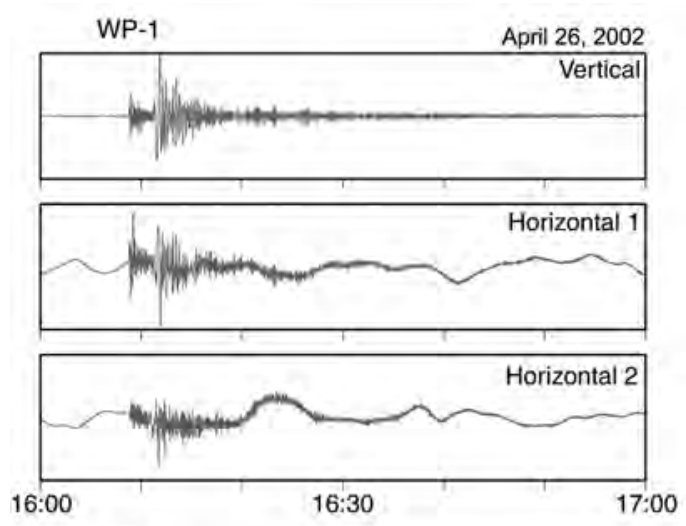

WP-2
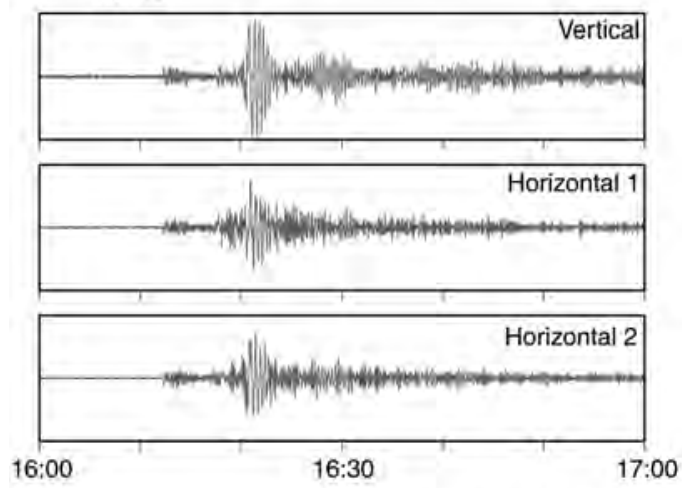

Origin: 2002 April 26 16:06:08 UTC 13.404N 144.599E $86 \mathrm{~km} m_{\mathrm{n}}=6.6$ Mariana Islands tical component of the WP-2 Observatory was damaged during installation. Although the JT-1 observatory has a peak in noise levels near a period of $100 \mathrm{~s}$ in the horizontal component, the WP-2 Observatory has no such peak. This peak is explained by the ocean gravity wave, and we infer that WP-2 escapes from the noise due to installation into the basement deep below the seafloor (Araki et al., 2004). The noise levels recorded by the horizontal component for periods greater than $10 \mathrm{~s}$ in the WP-1 Observatory are larger than those in the other observatories. Sensor coupling or mechanical problems may ac-

Fig. 11. The records of earthquakes observed simultaneously by both the WP-1 (upper) and the WP2 (lower) observatories. A one hour records of all the component from 16:00:00, April 26, 2002 are shown. No filter is applied. The earthquake occurred in Mariana region and its magnitude was 6.6.

Fig. 12. Magnitude distribution of earthquakes recorded by the WP-2 Observatory from October 29, 2000 to January 21, 2001 with epicentral distance (large symbols). Plus signs and dots refer to body wave magnitude determined by the USGS. Solid circles and squares relate to surface wave magnitude. Small dots and squares denote the magnitude of earthquakes by the USGS, which were not detected by the WP-2 Observatory. Almost all events with magnitudes greater than 5 are observed in the borehole observatories.

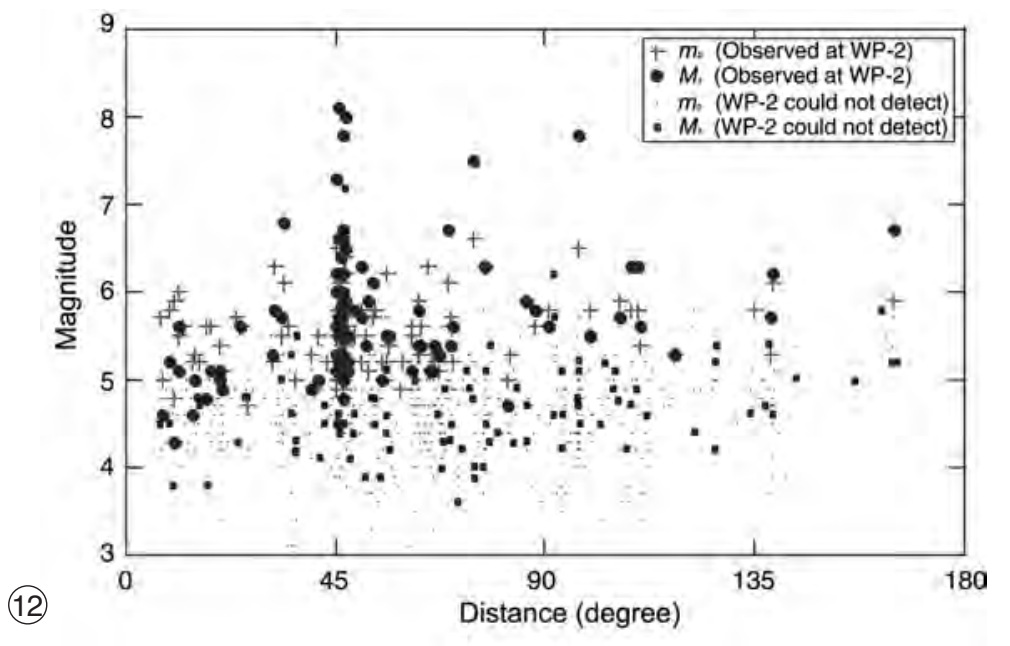



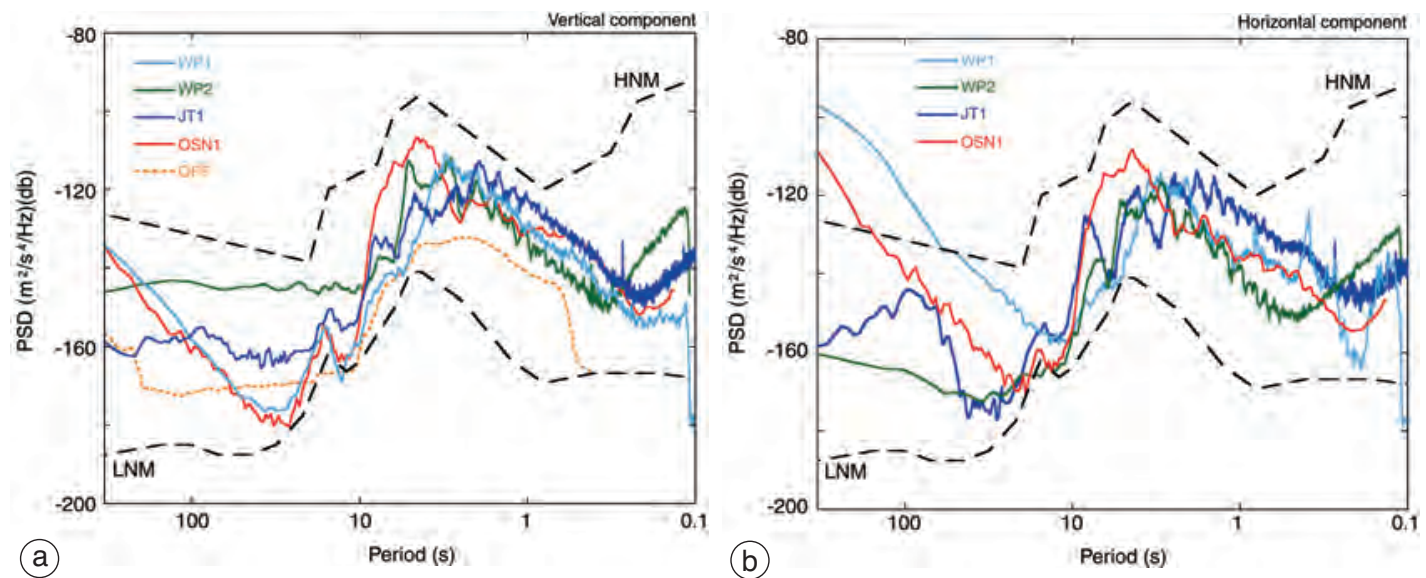

Fig. 13a,b. Comparison of ambient seismic noises between the station in this study and those in previous studies: a) for vertical component; b) for horizontal component. OFP and OSN-1 indicate borehole observatories in North Atlantic Ocean (Montagner, 1994) and the Pacific Ocean off Hawaii (Stephen et al., 1999), respectively. At present, observations at both these stations have been discontinued. HNM and LNM indicate the high noise model and the low noise model by Peterson (1993), respectively. The noise levels of the WP-1 and WP-2 observatories are comparable with those of the previous studies. There is no horizontal record for the OFP.

count for these results from the WP-1 Observatory. Generally, the noise levels of the WP-1 and the WP-2 observatories are comparable with those of previous observations in seafloor boreholes and land seismic stations. We confirm that seismic observation in deep-sea boreholes gives the best environment for earthquake observation in marine areas.

\section{Conclusions}

In 2000 and 2001, the seafloor borehole seismological observatories WP-1 and WP-2 were successfully installed in the northwestern Pacific. The WP-1 site is in the west Philippine Basin west of the Kyushu-Palau ridge. The WP-2 Observatory is situated on normal oceanic Mesozoic crust in the northwestern Pacific Basin. Both observatories fill important observational gaps in the worldwide seismic network, since no other land site can replace these sites. Each observatory has two identical broadband seismometers, which are cemented near the bottom of the hole. The WP-1 Observatory was activated in March 2002. At present, seismic records of 408 days in total have been obtained from the WP-1 Observatory. The WP-2 Observatory was activated in October 2000. Approximately fourteen-months of data were retrieved from the WP-2 Observatory.

The long-term variations of broadband seismic noise spectra $(3 \mathrm{mHz}-10 \mathrm{~Hz})$ in the northwestern Pacific Basin were revealed. The noise level above a period of about $10 \mathrm{~s}$ is stable in time. The vertical component of WP-2 has noise levels of about $-145 \mathrm{db}$. Noise levels for the horizontal component in WP-2 are lower than that of the vertical component $(-160 \mathrm{db}$ in periods greater than $100 \mathrm{~s}$ ). Because there is a possibility that this vertical sensor was damaged, we activated an alternative seismometer and shut down the sensor that had been used during the third ROV visit. It is found that the noise levels of the vertical component at WP-1 reach $-180 \mathrm{db}$ in periods between $10 \mathrm{~s}$ and $100 \mathrm{~s}$. On the other hand, small temporal variations (maximum fluctuation is $10 \mathrm{~dB}$ ) of noise levels in periods around a few seconds are seen; the WP-1 station and the WP2 Observatory have higher noise levels in summer and in winter, respectively. From comparison with meteorological data observed at a small island near the WP-1 Observatory, wind speed 
appears to be related to the noise levels in periods around a few seconds.

Due to the low seismic noise environment, many events were recorded in the records from both the deep-sea borehole observatories. It is possible to record teleseismic earthquakes with magnitude greater than 4.5 within an epicentral distance of $45^{\circ}$. We confirm that seismic observation in deep-sea borehole gives the best environment for long-term, low-noise, high-resolution earthquake observation in marine areas.

\section{Acknowledgements}

The success of the observations was made possible by the active co-operation of many scientists, engineers, technicians, ship officers and crew, and ROV operators from various institutions in the world. In particular, we express thanks to Drs. William W. Sager, Matthew H. Salisbury, Carlota Escutia, Carl Richter, Mr. Mike Storms and many people from ODP who led successful installations of the borehole observatories. The skillful maneuvers of the ROV by the KAIKO team, JAMSTEC are acknowledged. We thank Drs. Ralph A. Stephen, Hajime Shiobara, Hitoshi Mikada, Kenji Hirata, Kimihiro Mochizuki, Messrs. Michio Arisaka, Masakazu Ito for fruitful discussions and active support on this study. We would like to thank two anonymous reviewers for their thoughtful reviews and helpful comments. The comments by Dr. Daniel Curewitz were also helpful for improving the English of this manuscript. This study was partly supported by the Ocean Hemisphere Project from the Ministry of Education, Culture, Sports, Science and Technology of Japan. Most of the figures were created using GMT (Wessel and Smith, 1998).

\section{REFERENCES}

Araki, E., M. Shinohara, I.S. Sacks, A. Linde, T. Kanazawa, H. Shiobara, H. Mikada and K. SuyehiRO (2004): Improvement of seismic observation in the ocean by use of seafloor boreholes, Bull. Seismol. Soc. Am., 94, 678-690.

BEAuduin, R. and J.P. Montagner (1996): Time evolution of broadband seismic noise during the French pilot experiment OFM/SISMOBS, Geophys. Res. Lett., 23 (21) 2995-2998.
Collins, J.A., F.L. Vernon, J.A. Orcutt, R.A. StePhen, K.R. Peal, F.B. Wooding, F.N. SPIESS and J.A. HiLdBRAND (2001): Broadband seismology in the oceans: lessons from the ocean seismic network pilot Eexperiment, Geophys. Res. Lett., 28 (1), 49-52.

Hasvold, Ø., H. Henriksen, E. Melver, G. Citi, B.Ø. JoHENSEN, T. KJøNIGSEN and R. GALETTI (1997): Sea-water battery for subsea control systems, J. Power Sources, $\mathbf{6 5}$, 253-261.

ION/OdP INTERNATIONAL WORKSHOP (1995): Multidisciplinary Observatories on the Deep Seafloor, Marseille (France).

Kanazawa, T., K. Suyehiro, N. Hirata and M. Shinohara (1992): Performance of the ocean broadband downhole seismometer at Site 794, Proc. ODP, Sci. Results, 127/ 128, pt2, 1157-1171.

KanaZaWA, T., W.W. SAgER, C. Escutia and Shipboard SCIENTIFIC PARTY (2001): Northwest Pacific seismic observatory and Hammer Drill tests, Sites 1179-1182, Proc. ODP, Init. Rep., 191 (CD-ROM).

Montagner, J.P., J.F. Karczewski, B. Romanowicz, S. Bouaricha, P. Lognonné, G. Roult, E. Stutzmann, J.L. Thirot, J. Brion, B. Dole, D. Fouassier, J.C. Koenig, J. Savary, L. Floury, J. Dupond, A. Echardour and H. FLOC'H (1994): The French pilot experiment OFM-SISMOBS: first scientific results on noise level and event detection, Physics Earth Planet. Inter, 84, 321-336.

Peterson, J. (1993): Observations and modeling of seismic background noise, US Dep. Inter. Geol. Surv, Open-File Rep. 93-322.

Romanowicz, B., D. Stakes, J.P. Montagner, P. Tarits, R. Uhrhammer, M. Begnaud, E. Stutzmann, M. PasyaNOS, J.F. KARCZEWSKI, S. ETCHEMENDY and D. NEUHAUSER (1998): MOISE: a pilot experiment towards long term seafloor geophysical observatories, Earth Planets Space, 50, 927-937.

SACKS, I.S., K. SUYEHIRO, G.D. ACTON and SHIPBOARD SCIENTIFIC PARTY (2000): Western Pacific Geophysical Observatories, Sites 1150 and 1151, Proc. ODP, Init. Rep., 186 (CD-ROM).

SAlisbury, M.H., M. ShinOHARA, C. Richter and ShIPBOARD SCIENTIFIC PARTY (2002): Seafloor observatories and the Kuroshio current, Proc. ODP, Init. Rep., 195 (CD-ROM).

StePhen, R.A., J.A. Collins and K.R. PEAL (1999): Seafloor seismic stations perform well in study, Eos, Trans. Am. Geophys. Un., 80, 592.

Suyehiro, K., T. Kanazawa, N. Hirata, M. Shinohara and H. KinOSHITA (1992): Broadband downhole digital seismometer experiment at Site 794: a techinical paper, Proc. $O D P$, Sci. Results, 127/128, pt2, 1061-1073.

Suyehiro, K., E. Araki, M. Shinohara and T. KanazaWa (2002): Deep-sea borehole observatories ready and capturing seismic waves in the Western Pacific, Eos, Trans. Am. Geophys. Un., 83 (621), 624-625.

WEBB, S.C. (1998): Broadband seismology and noise under the ocean, Rev. Geophys., 36, 105-142.

WeSSEL, P. and W.H.F. SMITH (1998): New improved version of the generic mapping tools released, Eos, Trans. Am. Geophys. Un., 79, 579.

WiLCOCK, W.S.D., S.C. WeBB and I.T. BJARNASON (1999): The effect of local wind on seismic noise near $1 \mathrm{~Hz}$ at the MELT site and on Iceland, Bull. Seismol. Soc. Am., 89, 1543-1557. 